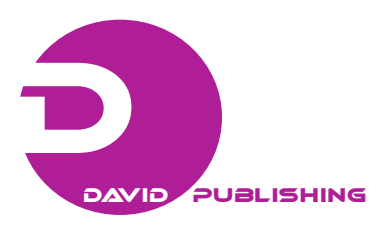

\title{
Improving Open Spaces for a Sustainable City
}

\author{
Karin Schwabe Meneguetti and Renato Leão Rego \\ Department of Architecture and Urbanism, Universidade Estadual de Maringá, Maringá 87010-340, Brazil
}

\begin{abstract}
The feasibility of city living with nature as a way to restore the balance between human uses and natural processes is the focus of this paper about the city of Maringá in Southern Brazil. This urban form, a planned new town founded in 1947 upon a previous, comprehensive British land-development scheme, originally offered a friendly interaction between urban settlement and nature. Hence, this paper outlines how open spaces can be enhanced as an ecological structure, bringing parks, squares, gardens and urban farming into a productive system, both for nature's and for people's sakes. Following a morphological study, the proposed ecological structure will maintain ecological processes within the urban grid and help to preserve historical and social values, by linking a wide variety of natural and restored ecosystems and landscape features. The adoption of this kind of ecological planning will certainly result in an increase of the urban landscape quality, changing actual planning paradigm and preventing the city from environmental quality decrease.
\end{abstract}

Key words: Open spaces, townscape, garden city, ecological structure, morphological studies.

\section{Introduction}

The original urban form of Maringá has possessed outstanding environmental qualities since its inception as a planned new town. A large proportion of open spaces, plazas and parks, the generous size of lots and wide roads, and the peculiarity of the town layout remain as positive qualities that differentiate the city. Its urban sprawl, however, has not emulated the original urban pattern. The unequal distribution of open spaces in the urban fabric can be easily seen - the best-urbanized and most usable squares and parks are basically found within the area of the original town layout.

This new Brazilian town was founded in 1947 as part of a previously-established, comprehensive British land-development scheme. Within a context of British imperialist initiatives, a London-based company started a land speculation business in the Northern region of Paraná State, buying a huge tract of land and planning a cluster of cities to support the developing rural plots. The profits of the business were to be

Corresponding author: Karin Schwabe Meneguetti, Dr., professor, research fields: landscape ecology, urban morphology and open spaces system. E-mail: ksmeneguetti@uem.br. significantly increased over time through the foundation of new towns and the construction of a railway line to connect them. Thus, the British company not only initiated a systematic colonization process in the remote undeveloped territory where Maringá was founded, but also carried out a deliberate urbanization process [1].

Formal aspects of the English garden city can be noticed in Maringá's original layout (as shown by Rego [2], Steinke [3], Andrade [4] and Macedo [5] and in accordance with Unwin [6] (Fig. 1). Maringá's designer, the civil engineer Jorge de Macedo Vieira, had previously worked with Barry Parker in late 1910s, when the British planner was in São Paulo for the design of new suburbs. Hence, Raymond Unwin's recommendations for town planning were thoroughly followed: an individual organic urban form with a multi-nuclei structure and low density was established, a monumental crescent-shaped civic centre was positioned at the core of the urban form, the central area was grid-based, following the formal aspect of town centres and the flat terrain and, in residential areas, hierarchical winding streets were laid out according to topographic features. Basically, natural features were considered as a major focus of Maringá's 


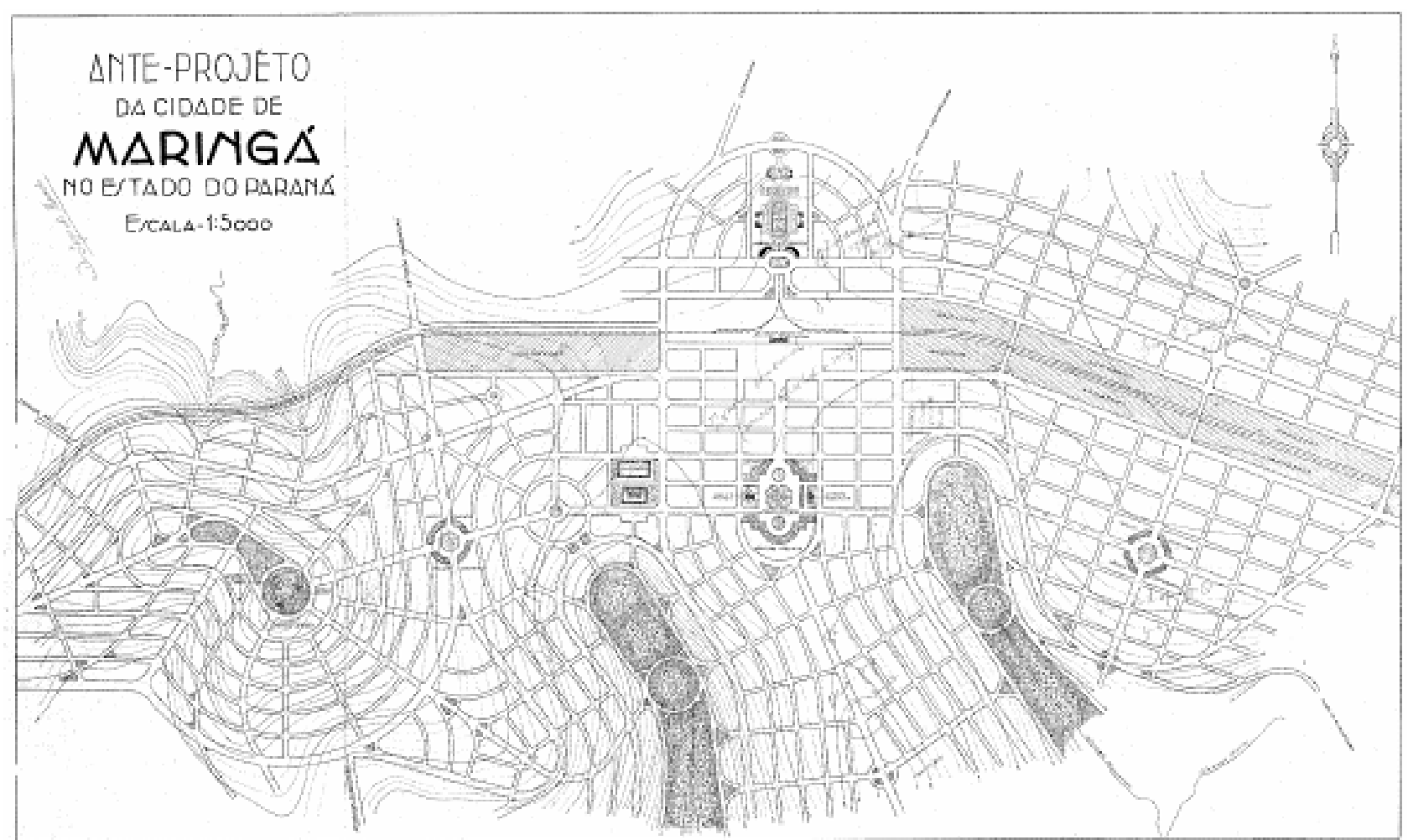

Fig. 1 The original design for Maringá.

Source: Prefeitura do Município de Maringá.

town planning. Urban parks were created around the springs of the city's two main streams, functioning as "the town's lungs". Avenues and streets also hosted natural features, with each public road originally receiving a particular specimen of tree, so that street identity was enhanced while the town itself recalled a garden [7].

Not only environmental issues were taken into account, but aesthetical aspects, along with functional and sanitary issues, also played a fundamental role in the planning of the new urban form. Thus, the organic, garden-city-like layout was the result of the built environment's adaptation to the site. According to Hardy [8], looked at holistically, the garden city is, even today, worth re-visiting as a model for a potentially sustainable settlement. As a result, the layout of Maringá created a unique, high quality, townscape [9], coherent with the environmental processes that were to become widely recommended from the second half of the twentieth century onwards.
But the city grew more than expected. Two subsequent master plans established the fundamental connectivity for, and the sustainability of, the green patches seen in the original layout, by imposing stream-preservation corridors. The city's first master plan, prepared in 1967 by the state government, was intended to regulate urban expansion, but the city grew still further. The plan outlined environmental protection areas along urban rivers, which can be considered the genesis of what today constitute the existing "green corridors". The second important plan for the city was the 1979 Guidelines for a road plan, which advanced the layout of new land parcelling, the design of green corridors along streams and the protection of remaining urban forested areas, influence of McHarg's Plan to the valleys can possibly be noticed in this plan [10]. Although the city had grown without complying with its original standards, the 1979 Plan did at least guarantee the existence of the main green corridors along the rivers and the widths of the avenues that cut across the urban fabric. Moreover, 
open spaces were connected to the green corridors, which enabled the possibility of a totally interconnected system. In the end, the initial intentions for the city and the later incipient efforts to make Maringá's urban form consonant with environmental processes became the basis for an environmentally friendly urban structure.

Despite this potential, even nowadays the city's open spaces are not recognized for the diversity of roles they could play and their maintenance is in a very precarious situation. Few appropriate open spaces have been created in new neighbourhoods. Only recently were these open spaces understood as being part of a system or structure [11].

The implementation of a management model for the system as a whole, and for the individual spaces as parts of it, can still turn them into a structure that is consistent with the urban qualities of the original design.

\section{Open Spaces as the Place of Nature in the City}

Public open spaces can create a system responsible for the conservation of the land and its resources, its ecology, parks and recreation areas as well as its historic or scenic urban areas. However, open spaces tend to be the most vulnerable spaces in the urban area, as they are constantly interpreted as being "empty" spaces just waiting to be built upon and occupied for some other reason. Often neglected by city management, they normally become the targets of real estate interest and surrender to other systems, such as the road system, eventually succumbing to a lack of appreciation of their originally determined roles. Likewise many other cities, Maringá has examples of this tragic transformation of open spaces [11].

Nevertheless, the most important role of open spaces is to be a place for nature in the city, for they have the ability to establish a balance between human necessity and the flow of nature. Parks, plazas, permeable areas and even sidewalks function as a form to protect environmental resources by restoring hydrological balance, improving air quality, defending sensitive areas and areas set aside for specific uses.

Moreover, forested areas help reduce the percentage of runoff of rainwater and its impact, as it was intended with the urban parks in the original town layout. Trees also help to cool built-up areas. In fact, tree cover can tame the effects of heat islands, by helping to control the microclimate in different ways [9]. Trees also provide habitat for birds and other animals that bring life to the city. The destruction or lack of urban forests results in the destruction or lack of the benefits they provide, both to people and nature. Strategic conservation through ecological structure can help communities recover from the effects of such devastation, identifying and protecting places where trees and other plant species grow [9].

Fig. 2 shows the current status of open spaces in Maringá. It can be noticed that the majority of these spaces are concentrated within the limits of the original city plan, i.e., the central area. In the areas of urban expansion, especially in the north of the urban form, a large number of roundabouts and valley bottoms create spaces for nature, in accordance with the 1979 Plan. This figure shows that during the expansion of the city, there was no concern about the allocation of areas for recreational use, only for the forested areas whose occupation was prohibited by environmental laws, consequently generating peripheral parks.

In most of the housing developments after 1970, areas targeted for public use were used for urban infrastructure and therefore the demand for leisure and recreation areas was not considered [12]. The potentiality of the green structure offered by Maringá's urban form can thus be improved.

\section{Improving Open Spaces}

As far as this paper is concerned, landscape should be understood as the interface between human and natural processes [12]. Since open spaces are believed 


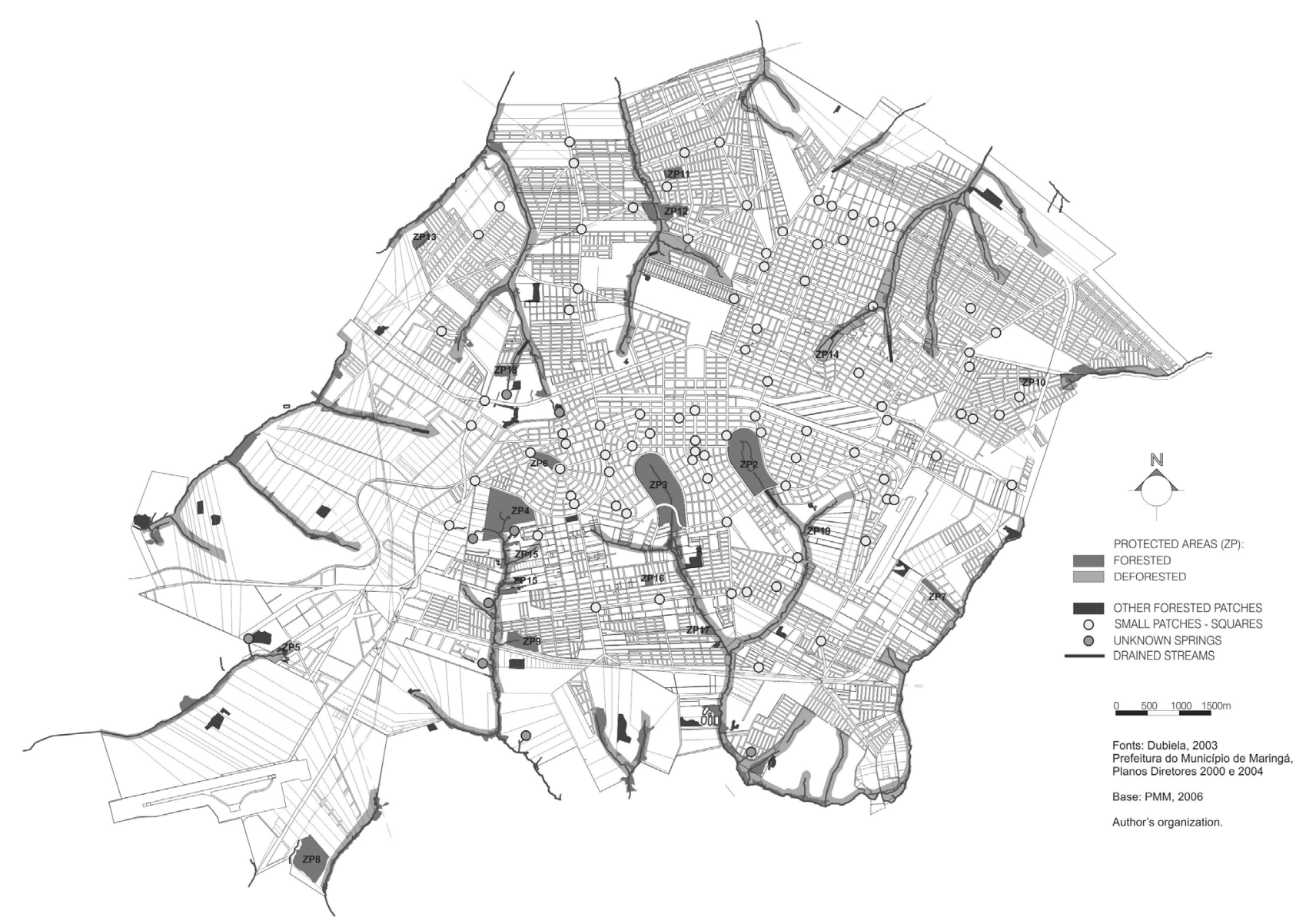

Fig. 2 Open spaces-current situation.

Source: Meneguetti [9].

to be the key to a more sustainable urban landscape, landscape ecology approach [13] can enhance these spaces to create an ecological structure that can allow natural processes within a built-up environment, which is a condition for an improved urban context.

It is essential to take the concepts of ecology onto the streets. When landscapes are designed and developed as part of a "high performance infrastructure" [14], they may not be able to protect the city and its citizens against the most catastrophic scenarios, but they can increase the strength and resilience of urban ecosystems in the face of a wide range of disturbances which, over time, are unavoidable.

Likewise, this ecological framework can be used to drive future growth and future decisions about urbanization and land conservation in order to accommodate population growth and to protect and preserve community assets and natural resources [9].

By applying these ecological planning principles to Maringá, the potential for the implementation of an urban ecological structure onto the network of existing open spaces was identified, as shown in Fig. 2. As they are already regularly distributed all over the urban tissue, despite the best-quality spaces are concentrated in the central area as discussed previously, they can systemically enable an ecological structure, which can increase significance of the landscape and allow sustainability. They can also serve the needs of urban infrastructure, especially those related to drainage and water quality. Any urban form can be optimised by taking an ecological-structural approach, especially when a system of open spaces that support conservation and human values, and guide future growth, thereby preventing sprawl, is created [15]. The 
formal principles of the garden city in Maringá's original layout have potentially created the basis for this ecological structure.

Additionally, Maringá's road system is also a purveyor of important green corridors, which provide a different means of connectivity. On the one hand, the trees that line Maringá's streets and avenues are a landmark of the city. Their blossoms are an important factor in the town's image and birds dominate their continuous canopy. Furthermore, the shade of the trees improves the urban microclimate, moderating the heat-island effect. On the other hand, the increasing number of "ecological sidewalks", which is the grassy area along the sidewalks that reduce surface runoff and enhance the trees' survival, has had a positive impact on the built-up urban environment.

The ecological structure was designed onto this pre-existing system, following the morphological study, as shown in Fig. 3. That means that the elements responsible for this green connectivity and for conducting storm water and biodiversity were inserted into and between the structures that are already evident in the existing system, thus creating open spaces compatible with leisure activities and the social life of the community, and thus being able to supply the environmental services that are required within the city. They will also optimize the open spaces and enable them to perform these services. Moreover, they will improve the welfare of the community and increase the aesthetic and environmental qualities of the place they live in. By providing connections to the landscape, protecting historic resources and incorporating community values in the planning, ecological structure can thus enhance community pride and quality of life [15].

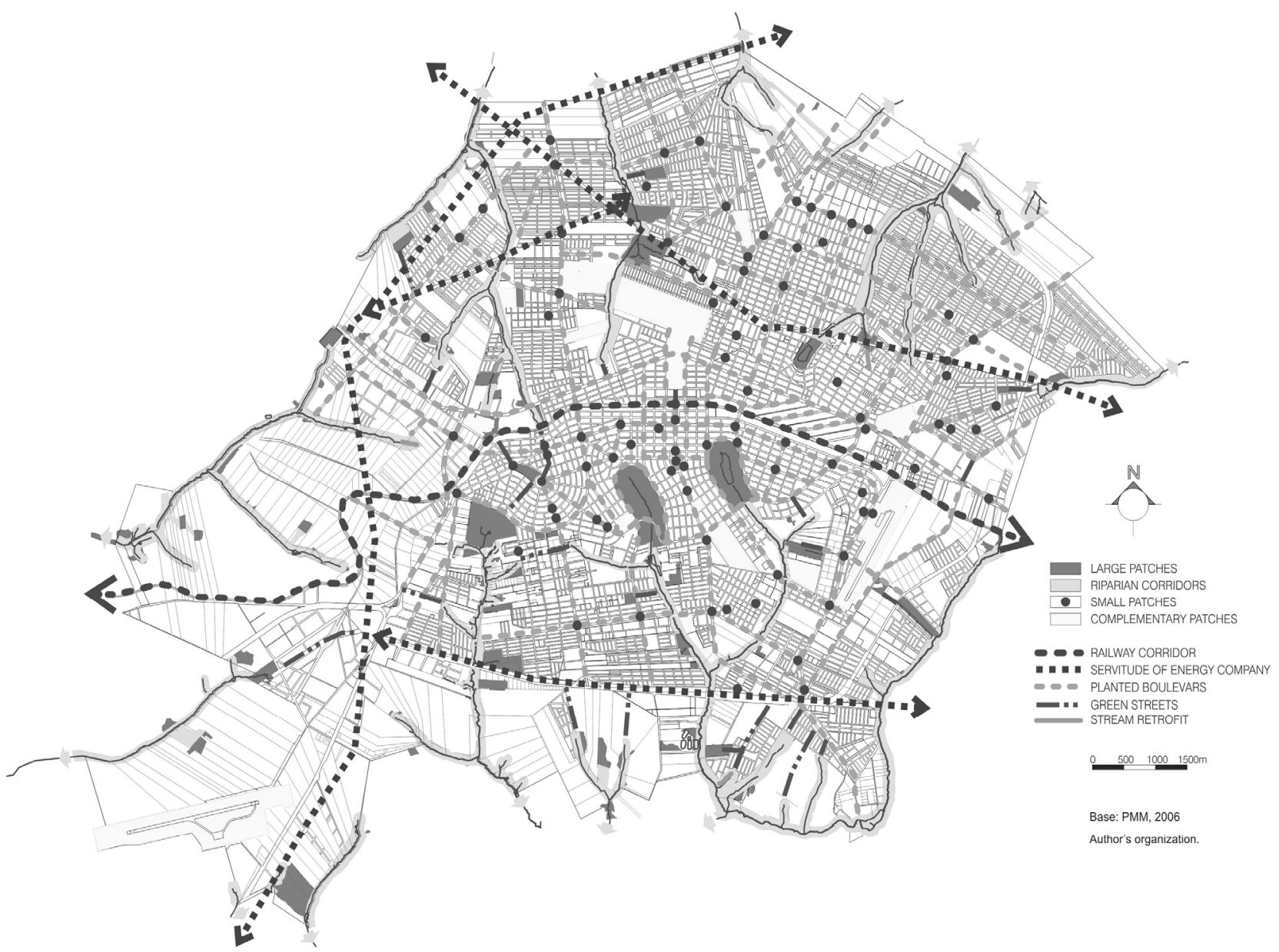

Fig. 3 The ecological plan for Maringá.

Source: Meneguetti [11]. 
The proposed ecological structure includes large public or semi-public areas, namely, clubs, parks and squares, large forested areas, riparian areas, including rivers, streams and drainage lines, areas for service companies, buffers to protect railway-line transportation corridors, and avenues and streets covered by trees. Some of these elements already exist, as previously shown in Fig. 2, and their conservational importance is obvious. Others can be added, and will perform complementary roles by enhancing their ability to shelter natural processes. Community initiatives, particularly common-ground urban farms on open spaces, can also collaborate. Each of these elements can contribute differently to the ecological structure. However, their general purpose will be to create more green spaces for leisure activities and community life, increase respect for wildlife and conserve of biodiversity, augment soil permeability and improve conduction of pluvial water, improve air quality, create shaded areas in order to prevent isles of urban heat, and reduce the impact of carbon-dioxide-levels on the local atmosphere and on global warming as well.

Biodiversity, as suggested by Benedict et al. [15], can then be protected through the identification, analysis and scientific preservation of natural diversity within the landscape, by redirecting urbanization around these rare natural elements within the landscape, thereby protecting the large contiguous and connected areas containing the critical habitats and reducing negative edge effects and the invasion of exotic species.

Each element, though integrated and working together with the rest of the structure, has a distinct role and is intended to perform a specific environmental function. Some examples, as detailed by Meneguetti [11], are:

(1) Stream valleys: areas containing streams and strips of riparian forest, and other such plains, borders and areas adjacent to perennial watercourses or temporary drainage lines, lakes and wetlands.
According to current legislation, these areas must have riparian forests or other such natural features, such as linear parks. Recreational and leisure activities should preferably be located on paths bordering these scenic corridors so as to integrate them with urban roads. The primary function of these areas is the protection of the bodies of water, filtering and purifying rainwater, and creating natural habitats and transportation links for animal species. The vegetation, therefore, should consist of native species and be a continuous strip;

(2) Public squares, recreation and leisure areas: these must have their permeable areas extend as far as possible, and have rainwater detention and retention systems installed. With the participation of local communities, they can be turned into models for the exploration of such alternative systems. The afforestation of these areas with native and predominantly zoochoric species will turn them into environmental stepping stones, small areas that facilitate the movement of species across the landscape, thereby increasing connectivity between other elements outside of the city;

(3) Street arborisation: because of the importance of street arborisation for the image and urban environment of Maringá, the municipality must enact a specific plan to ensure the continuity of the trees along its streets, in order to ensure the connections between the remaining areas of nature within the urban perimeter and their ecological continuity. As avenues have at least three rows of trees (one along each of the sidewalks and another along the median strip) and allow the planting of various strata in between the trees, they must be the primary object of a such project to create green connection corridors.

\section{Conclusions}

The comprehensive ecological structure proposed in this paper redevelops urban open spaces in order to ecologically, socially and economically revitalize Maringá's urban form. It will allow city and nature to coexist in a complementary manner in the urban 
landscape, ensuring the permanence of urban ecosystems and thereby improving the environmental quality of urban life.

The environmental elements that were created in the original plan for the city of Maringá, endorsed in its subsequent plans to a certain extent, ensured the existence of a potential system of open spaces whose improvement as an ecological structure can meet the goals of conserving natural resources and balancing the natural processes within the city. The original town layout created not only a unique urban form but also environmentally friendly conditions for urban settlement. These conditions spared the city from uncontrolled growth, which was then the current practice in the majority of Brazilian towns. The garden-city-like urban form of Maringá is therefore a model for a potentially sustainable settlement, proving that the garden city idea is, even today, worth re-visiting.

The general layout of the ecological structure presented here must now be detailed in the form of specific plans. Thus, implementation plans will adopt specific focuses, such as stormwater management, recreational areas, alternative transportation, etc.. The adoption of this kind of ecological planning will certainly result in an increase in the value of the urban landscape, by enhancing the distinctive historical traces of the former garden city. Moreover, increased opportunities for recreational land use and a sense of community will be created.

\section{Acknowledgments}

The preliminary version of this article has been presented at EAAE/ISUF International Conference "New Urban Configurations"-ISUF 2012 in Delft, Netherlands.

\section{References}

[1] R.L. Rego, K.S. Meneguetti, British urban form in twentieth-century Brazil, Urban Morphology 12 (1) (2008) 25-36.

[2] R.L. Rego, The urban design of Maringá and the idea of the garden city, Acta Scientiarum 23 (6) (2001) 1569-1577. (in Portuguese)

[3] R. Steinke, Curving Streets Versus Straight Streets, EdUEM (Editora da Universidade Estadual de Maringá), Maringá, 2007. (in Portuguese)

[4] C.R.M. Andrade, Garden-city resonances in new towns planning in Brazil, in: Seminar on History of the City and Urbanism, Porto Alegre, 2000.

[5] J. Macedo, A British City in the tropics, Cities 28 (2011) 347-359.

[6] R. Unwin, Town Planning in Practice: An Introduction to the Art of Designing Cities and Suburbs, Gustavo Gili Editorial S.A., Barcelona, 1984. (in Spanish)

[7] K.S. Meneguetti, R.L. Rego, A study on the interaction between town layout and nature: The urban landscape of Maringá, Brazil, in: Proceedings of International Seminar on Urban Form, Artimino, 2008.

[8] D. Hardy, Cities That Don't Cost the Earth, Town and Country Planning Association, London, 2008.

[9] K.S. Meneguetti, Garden City, Sustainable City, The Urban Ecological Structure and the City of Maringá-PR, EdUEM, Maringá, 2009. (in Portuguese)

[10] I.L. McHarg, Design with Nature, John Willey \& Sons, New York, 1992.

[11] K.S. Meneguetti, From garden city to sustainable city, potentialities for an urban ecological structure in Maringá-PR, Ph.D. Thesis, Faculty of Architecture and Urbanism, University of São Paulo, 2007. (in Portuguese)

[12] K.S. Meneguetti, Urban design and quality of life-The case of Maringá-PR, Master's Thesis, State University of Maringá, 2001. (in Portuguese)

[13] R.T.T. Forman, M. Godron, Landscape Ecology, John Wiley \& Sons, New York, 1986.

[14] M. Vogel, Moving toward High-Performance Infrastructure, Urban Land Plan, Oct. 2006, pp. 73-79.

[15] M.A. Benedict, E.T. Mcmahon, Green Infrastructure, Linking Landscapes and Communities, Island Press, Washington, DC, 2006. 